\title{
Composite Diametral Tensile Strength
}

\author{
${ }^{1}$ Ali AR Al-Shekhli, ${ }^{2}$ Isra'a Al Aubi
}

\section{ABSTRACT}

Aim: The aim of this study was to evaluate and compare the diametral tensile strength (DTS) of 4 types of composite materials including bulk fill type (tetric evo ceram) cured with two different curing intensities.

Materials and methods: Four types of light-activated composite materials of $A 3$ shade were selected for this study: Tetric Evo Ceram-Ivoclar Vivadent; Ceram X.mono- Dentsply; Nano Ceram-Bright-DMP; Estelite Sigma Quick-Tokuyama. Twenty specimens of each composite material were prepared: ten specimens were cured with high intensity $1200 \mathrm{~mW} / \mathrm{cm}^{2}(\mathrm{n}=10)$ (high-intensity group) for 20 seconds and ten specimens were cured with low intensity $650 \mathrm{~mW} / \mathrm{cm}^{2}(\mathrm{n}=10)$ (low intensity group) for 20 seconds. Specimens were prepared following the ISO 4049 and ADA/ANSI 27 Specifications in which cylindrical specimens ( $n=20$ of each material) of $4 \mathrm{~mm}$ in depth and $6 \mathrm{~mm}$ in diameter were prepared and stored in distilled water for 24 hours at $37^{\circ} \mathrm{C}$. The DTS test was performed using the universal testing machine (Testometric/UK) with a crosshead speed of $1.0 \mathrm{~mm} /$ minute. The specimens were placed with their long axes perpendicular to the surface of the applied compressive load until failure. Values of the DTS in MPa were calculated and statistically analyzed by one way analysis of variance (ANOVA) and Tukey tests at 95\% level of significance.

Results: The mean of DTS in the high-intensity group ranged from 38.49 to $48.79 \mathrm{MPa}$, whereas the mean of DTS in the lowintensity group ranged from 24.58 to $38.15 \mathrm{MPa}$. The $p$ values of statistical tests were all less than 0.05 . One-way analysis of variance (ANOVA) tests for DTS values of all the four composite groups cured with high intensity at $1200 \mathrm{~mW} / \mathrm{cm}^{2}$ and for DTS values of all the four composite groups cured with low intensity at $650 \mathrm{~mW} / \mathrm{cm}^{2}$ revealed that there were statistically significant differences $(p \leq 0.05)$.

Conclusion: Within the limitations of the study we can conclude that high-intensity curing significantly resulted in higher DTS values in all the composites being tested in this study due to a better degree of conversion and composite composition also significantly influences its DTS values.

Clinical significance: Diametral tensile strength (DTS) of any restorative material is an essential test that simulates the tensile behavior of the restorative material during function in the oral cavity which is an indicator for the general strength and durability of the restoration in oral service.

Keywords: Composite resin, Diametral tensile strength, Mechanical properties.

\footnotetext{
1,2Department of Restorative Dentistry, College of Dentistry, Ajman University, Fujairah Campus, UAE
}

Corresponding Author: Ali AR Al-Shekhli, Department of Restorative Dentistry, College of Dentistry, Ajman University, Fujairah Campus, UAE, e-mails: a.razook@ajman.ac.ae, alirazooki@yahoo.com
How to cite this article: Al-Shekhli AAR, Aubi IA. Composite Diametral Tensile Strength. World J Dent 2018;9(6):457-461.

Source of support: Nil

Conflict of interest: None

\section{INTRODUCTION}

One of the most important discoveries in the history of operative dentistry was the improvement of lightactivated composite resin for direct restorations, and this material has revolutionized this field in a way that today restorative dentistry cannot be imagined without dental composite. ${ }^{1,2}$

The demand for lifelike appearance makes the patients looking for tooth-colored restorations in anterior and posterior teeth similarly. ${ }^{3}$ Skinner in 1959 wrote, "the esthetic quality of restoration may be as important to the mental health of the patient as the biological and technical qualities of the restoration are to his physical or mental health." And till today esthetic considerations are still the primary reason for demanding dental treatment. $^{3}$

Requirements for filling materials include the physical properties and wear resistance should be close to that of the tooth structure, good optical properties, detectable on X-ray, easy to handle and to polish, have the ability to bound to tooth structure, should be tasteless and biocompatible, and many more of these requirements are recorded in the ISO (4049) standards. ${ }^{4}$

For a successful composite restoration, properties like diametral tensile strength, compressive strength, flexural strength, the linear coefficient of thermal expansion, water sorption, wear resistance, surface texture, radioopacity, modulus of elasticity, solubility, must be optimal. ${ }^{3}$ Such mechanical properties affect dental composite, whether to be used in the anterior or posterior region. ${ }^{5}$

Because of the improvement of this material, it gives us the advantages to be used for restoring posterior stressbearing cavities, and as an alternative to amalgam. ${ }^{6}$ The first attempt to put composite in posterior teeth was not successful because of inadequate mechanical properties, such as inadequate resistance to wear, fracture within the body of the restoration, and microleakage due to polymerization shrinkage, were the most common cause of failure in posteriors teeth, but some of those disadvantages have been greatly overcomed in the last few years. Improvements in the material properties along with the clinical 
performance encourage the practitioner to use composite resin in posterior teeth as an alternative to amalgam. ${ }^{6}$

Tensile strength is the force needed to break a material when the material is subjected to two sets of forces that are directed away from each other in the same straight line, diametral tensile strength testing was developed to investigate brittle material such as, composite, with little or no plastic deformation. ${ }^{5}$

The aim of this study was to evaluate and compare the DTS of four types of light activated composite materials (Tetric Evo Ceram-Ivoclar Vivadent as a bulkfill type; Ceram X.mono-Dentsply; Nano Ceram-Bright-DMP; Estelite Sigma Quick-Tokuyama) cured with two different light activation intensities.

\section{MATERIALS AND METHODS}

Four types of light-activated composite materials of A3 shade were selected for this study: [Tetric Evo Ceram (bulkfill)]-Ivoclar Vivadent; Ceram X.mono-Dentsply; Nano Ceram-Bright-DMP; Estelite Sigma QuickTokuyama). Twenty specimens of each composite material were prepared: ten specimens were cured with high intensity $1200 \mathrm{~mW} / \mathrm{cm}^{2}$ ( $\mathrm{n}=10$ ) (high-intensity group) for 20 seconds and ten specimens were cured with low intensity $650 \mathrm{~mW} / \mathrm{cm}^{2}$ ( $\left.\mathrm{n}=10\right)$ (low-intensity group) for 20 seconds. Eighty resin composite specimens were prepared ( $n=20$ of each type of composite material) by incremental (two increments) insertion of composite into a circular nickel-chromium split mold with $6 \mathrm{~mm}$ in inner diameter and $4 \mathrm{~mm}$ in height and cured using Blue phase G2 (Ivoclar, Vivadent) light curing unit for 20 seconds for each $2 \mathrm{~mm}$ increment of composite thickness except for Tetric Evo Ceram bulkfill composite the curing was done for the whole thickness of the composite specimen for 20 seconds (Fig. 1A). Following the ISO 4049 and ADA/ ANSI 27 specifications for standardized DTS testing in which cylindrical specimens of $6 \mathrm{~mm}$ in inner diameter and $4 \mathrm{~mm}$ in thickness have to be prepared (Fig. 1B). The specimens then stored in distilled water for 24 hours at $37^{\circ} \mathrm{C}$ before the mechanical testing. The DTS test was performed using the universal testing machine (Testometric/UK) with a crosshead speed of $1.0 \mathrm{~mm} /$ minute. The specimens were placed with their long axes perpendicular to the surface of the applied compressive load until failure (Fig. 1C).

The DTS was calculated using the equation: DTS = $2 \mathrm{~L} / \pi \mathrm{Dh}$, where $\mathrm{L}$ is the failure load, $\mathrm{D}$ the diameter, and $h$ the height of the specimen.
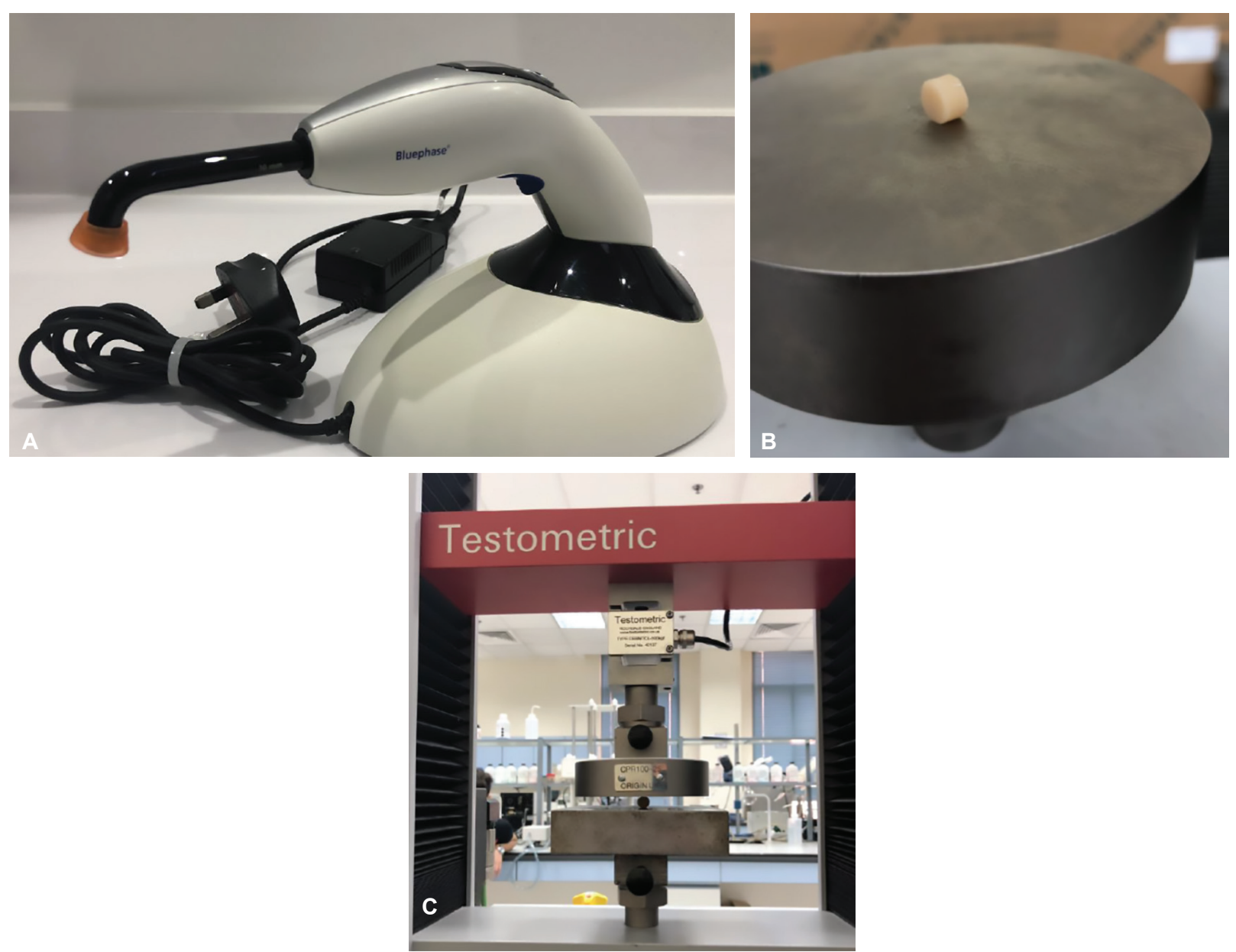

Figs 1A to C: Devices and composite specimen used in this study. (A) Blue phase G2 light curing unit; (B) Cylindrical composite specimen of $6 \mathrm{~mm}$ in diameter and $4 \mathrm{~mm}$ in height; (C) The universal testing machine (Testometric/UK) 
Mean DTS values were expressed in MPa and data were analyzed by t-test at the 0.05 level of significance.

\section{RESULTS}

Mean DTS values, standard deviations of the four composites with high and low intensity curing in MPa are presented in Table 1. Graph 1 represents the mean DTS values of the four composites being tested with high and low intensity curing in MPa.

One-way analysis of variance (ANOVA) tests for DTS values of all the four composite groups cured with high intensity at $1200 \mathrm{~mW} / \mathrm{cm}^{2}$ and for DTS values of all the four composite groups cured with low intensity at 650 $\mathrm{mW} / \mathrm{cm}^{2}$ revealed that, there were statistically significant differences $(p \leq 0.05)$ as shown in Tables 2 and 3, respectively.

Further analysis of the data with t-test indicated that, there was a statistically significant difference in DTS values between all the 12 pairs of the four groups cured with high and low intensities $(p \leq 0.05)$ except between pairs no. 5, 7, 9 and 11 that showed no significant differences between them as shown in Table 4 .

\section{DISCUSSION}

The main importance of diametral tensile strength testing came from it gives an indication about the resistance to fracture of restorative materials in clinical service, and minimizing the clinical problems associated with it. ${ }^{5}$

Table 1: Mean DTS values, standard deviations of the four composites with high and low intensity curing in $\mathrm{MPa}$

\begin{tabular}{lll}
\hline Intensity & Groups composite & DTS in MPa, (SD) \\
\hline High intensity & Tetric Evo Ceram & $48.799,(1.8)$ \\
$1200 \mathrm{~mW} / \mathrm{cm} 2$ & Bulk fill & \\
& Ceram X mono & $45.777,(1.4)$ \\
& Nanoceram - Bright & $38.494,(3.7)$ \\
& Estelite & $44.805,(1.2)$ \\
Low intensity & Tetric Evo Ceram & $38.150,(2.1)$ \\
$650 \mathrm{~mW} / \mathrm{cm} 2$ & Bulk fill & \\
& Ceram X mono & $37.764,(1.9)$ \\
& Nanoceram - Bright & $24.582,(3.2)$ \\
& Estelite & $35.935,(1.07)$ \\
\hline
\end{tabular}

Tetric EvoCeram achieved the highest DTS mean values among all the composite groups being tested in this study in both high and low-intensity groups while Nano Ceram-Bright composite achieved the lowest DTS mean values among all the composite groups being tested in this study in both high and low-intensity groups Table 1 and Graph 1.

The results obtained from the study were supported by the findings of Koplin and Takahashi who found that the values of the diametral tensile strength of Tetric Evo Ceram under high intensity to be $48 \mathrm{MPa}^{7,8}$ Moraes $^{9}$ reported a mean value of $46 \mathrm{MPa}$ for Tetric Evo Ceram under high-intensity curing. Probably the main reasons behind the high mean values of diametral tensile strength achieved by Tetric Evo Ceram bulk fill in this study might be attributed first to its resin composition as it contains Bis-GMA, Bis-EMA and UDMA Table 5. During the polymerization reaction, monomers are being converted into a long chain cross-linked polymer matrix. The organic matrix phase of Tetric Evo Ceram composite makes about $21 \%$ of the total mass. Tetric Evo Ceram composite is the result of a harmonious optimized monomer matrix and fillers combination. The second reason might be attributed to its magic mixture of different types of filler (two different mean particle

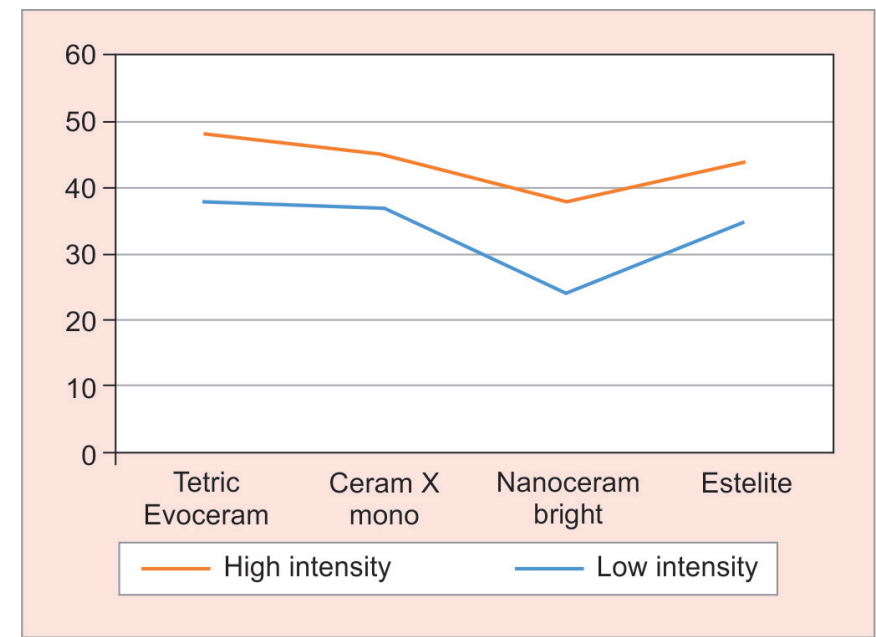

Graph 1: Mean DTS values of the four composites with high and low intensity curing in $\mathrm{MPa}$

Table 2: One-way analysis of variance (ANOVA) for DTS of all the four composite groups cured with high intensity $1200 \mathrm{~mW} / \mathrm{cm}^{2}$

\begin{tabular}{llllll}
\hline Source & SS & $d f$ & $M S$ & $F$ & $p$ \\
\hline Between-treatments & 581.2351 & 3 & 193.745 & 41.40083 & $<0.00001$ \\
Within-treatments & 168.4706 & 36 & 4.6797 & - & - \\
Total & 749.7057 & 39 & - & - & - \\
\hline
\end{tabular}

Table 3: One-way ANOVA for DTS of all the four composite groups cured with low intensity $650 \mathrm{~mW} / \mathrm{cm}^{2}$

\begin{tabular}{llllll}
\hline Source & SS & $d f$ & $M S$ & $F$ & $p$ \\
\hline Between-treatments & 1268.3934 & 3 & 422.7978 & 52.69384 & $<0.00001$ \\
Within-treatments & 288.852 & 36 & 8.0237 & - & - \\
Total & 1557.2454 & 39 & - & - & - \\
\hline
\end{tabular}


Table 4: t-test of the DTS values between different pairs of the four groups cured with high and low light intensities

\begin{tabular}{|c|c|c|c|c|}
\hline Intensity & Pair no. & Pair of groups & $t$ & Critical value 2.101 \\
\hline \multirow{6}{*}{ High intensity $1200 \mathrm{~mW} / \mathrm{cm}^{2}$} & 1 & G1 X G2 & 4.0203 & Sig. \\
\hline & 2 & G1 X G3 & 8.5585 & Sig. \\
\hline & 3 & G1 X G4 & 5.5453 & Sig. \\
\hline & 4 & G2 X G3 & 6.3833 & Sig. \\
\hline & 5 & G2 X G4 & 1.5555 & Not sig. \\
\hline & 6 & G3 X G4 & -5.6666 & Sig. \\
\hline \multirow{6}{*}{ Low intensity $650 \mathrm{~mW} / \mathrm{cm}^{2}$} & 7 & G1 X G2 & 0.4455 & Not sig. \\
\hline & 8 & G1 X G3 & 10.9051 & Sig. \\
\hline & 9 & G1 X G4 & 1.0797 & Not sig. \\
\hline & 10 & $\mathrm{G} 2 \times \mathrm{G} 3$ & 10.8789 & Sig. \\
\hline & 11 & $\mathrm{G} 2 \times \mathrm{G} 4$ & 0.7868 & Not sig. \\
\hline & 12 & G3 X G4 & -7.9164 & Sig. \\
\hline
\end{tabular}

Table 5: Comparison of materials properties provided by manufacturers

\begin{tabular}{|c|c|c|c|}
\hline Materials & Filler composition & Matrix composition & Shade and Batch \\
\hline $\begin{array}{l}\text { Tetric Evo Ceram Bulk Fill } \\
\text { Ivoclar-Vivadent (Schaan, } \\
\text { Liechtenstein }\end{array}$ & $\begin{array}{l}\text { - Ba-glass, YbF3, mixoxide, PPF } \\
\cdot 76 \%\end{array}$ & $\begin{array}{l}\text { - Nano-Hybird Bis-GMA, Urethane } \\
\text { dimethacrylate, Ethoxylated } \\
\text { Bis-EMA, UDMA }\end{array}$ & $\begin{array}{l}\cdot \text {-A3 } \\
\cdot \text { R56348 }\end{array}$ \\
\hline Ceram X mono (Dentsply) & - $76 \%$. & $\begin{array}{l}\text { - Nano- Fill } \\
\text { - Methacrylate modified polysiloxane } \\
\text { - Dimethacrylate resin }\end{array}$ & $\begin{array}{l}\cdot \text {-A3 } \\
\cdot 1405000969\end{array}$ \\
\hline $\begin{array}{l}\text { Nano Ceram-Bright } \\
\text { (DMP LTD) }\end{array}$ & $\begin{array}{l}\text { - Barium glass, mixed oxide. } \\
\text { - } 80 \% \text {. }\end{array}$ & - Nano-Hybrid, Bis-GMA, TEGDMA & $\begin{array}{l}\cdot \text {-A3 } \\
\cdot 630340 \\
\end{array}$ \\
\hline Estelite sigma quick & $\begin{array}{l}\text { - Silica-zirconia filler } \\
\cdot 82 \% \text { filler weight }\end{array}$ & $\begin{array}{l}\text { - Nano fill, Bis-GMA and Triethylene } \\
\text { glycol dimethacrylate }\end{array}$ & $\begin{array}{l}\text {-A3 } \\
\cdot \text { E839 }\end{array}$ \\
\hline
\end{tabular}

sizes, an "Isofiller" with barium aluminum silicate glass, ytterbium fluoride and spherical mixed oxide) to achieve the preferred composite physical and mechanical properties. Tetric Evo Ceram light activated composite has a standard filler content of approximately $61 \%$ by volume and 17\% "Isofillers" (Scientific Documentation Tetric Evo Ceram ${ }^{\circledR}$ Bulk Fill). ${ }^{10}$ The third reason might be attributed to its unique photoinitiator Ivocerin ${ }^{\circledR}$-a dibenzoyl germanium derivative ${ }^{11,12}$ which plays an important role in its optimum polymerization due to the optimal compatibility with Blue Phase G2 light curing unit as Ivocerin photoinitiator wavelength peak absorption values is with Blue Phase G2 light curing unit which was specifically designed to cure Ivoclar Vivadent composite products . It allows optimal curing of posterior composite restorations in larger single increment thickness of up to $4 \mathrm{~mm}$, without affecting the optical properties of the such as translucency or hue. The combined initiator system (camphorquinone) plus Ivocerin ${ }^{\circledR}$ results in a material featuring an absorption optimum in the blue light range from around 370 to $460 \mathrm{~nm} .^{13}$

The DTS of the high-intensity group was significantly higher than that of the low-intensity group (Graph 1). These findings were consistent with findings of other research like Rueggeberg ${ }^{14}$ who concluded that the higher the light intensity, the higher the degree of conversion, which results in improvement in the general properties of the dental composite, but might lead to increase in polymerization shrinkage. ${ }^{15,16}$

The findings of the current study is also in agreement with the findings of many other previous studies in that, the average DTS values for many conventional dental composites are fallen within our range $34-45 \mathrm{MPa}$ (Table 1) when cured with full light intensity and also we agreed with their justification for results obtained from their studies in that, "The diametral tensile strength test may reveal different values for apparently similar materials. However, this variation has been explained by the difference between the polymeric matrix, the size of fillers and bond between fillers and matrix. ${ }^{17}$ The matrix of most resins is composed of bisphenol-A glycidylmethacrylate (Bis-GMA), which is an aromatic ester of a dimethacrylate, synthesized from an epoxy resin and methyl methacrylate; thus, it is rigid yet presents high viscosity. The viscosity of the polymeric matrix is reduced by the addition of other low molecular weight polymers such as urethane dimethacrylate (UEDMA) or triethyleneglycol dimethacrylate (TEGDMA), as in the composite Filtek Z-250, to improve the incorporation of fillers and increase the degree of conversion of composite resins. Therefore, it has been reported that replacing BisGMA by TEGDMA increases the diametral tensile strength yet reduces the flexural strength, whereas replacing either Bis-GMA or TEGDMA by UEDMA increases the 
diametral strength and flexural strength, ${ }^{17}$ which was confirmed by the results in that study". In the current study, we also found that, replacing either Bis-GMA or TEGDMA by UDMA or incorporation of UDMA resin monomer in composite resin matrix composition) (Table 5) significantly increases the diametral tensile strength of many conventional composites, as in Tetric Evo Ceram composite, which was confirmed by the results obtained in the current study and also explained why Nano CeramBright composite exhibited the least DTS mean values among all the composite being tested in this study and supports and might be one of the main causes behind the high DTS mean values of Tetric Evo Ceram composite as it was mentioned before (Table 5). ${ }^{18-20}$

\section{CONCLUSION}

Within the limits of this study, we can conclude:

- High light intensity significantly resulted in higher DTS values in all the composites being tested than the low light intensity.

- The composite composition also significantly influences its DTS values.

\section{CLINICAL SIGNIFICANCE}

Diametral tensile strength (DTS) of any restorative material is an essential test that simulates the tensile behavior of the restorative material during function in the oral cavity which is an indicator for the general strength and durability of the restoration in oral service.

\section{REFERENCES}

1. Casselli M, Worschech C, Paulillo L, Dias C. Diametral tensile strength of composite resins submitted to different activation techniques. Braz Oral Res 2006;20:214-218.

2. Tolosa M, Paulillo L, Giannini M, Santos A, Dias C. Influence of composite restorative materials and light-curing units on diametrical tensile strength. Braz Oral Res 2005;19:123-126.

3. Jacobs J, Lilly M, Coyte P. The fiscal impact of informal caregiving to home care recipients in Canada: how the intensity of care influences costs and benefits to government. Social Science \& Medicine. 2013;81:102-109.

4. Zimmerli B, Strub M, Jeger F, Stadler O, Lussi A. Composite materials: composition, properties and clinical applications. A literature review. SSO. 2010;120(11):972-986.

5. Della A, Benetti P, Borba M, Cecchetti D. Flexural and diametral tensile strength of composite resins. Braz Oral Res. 2008; 22:84-89.
6. Manhart J, Kunzelmann K, Chen H, Hickel R. Mechanical properties and wear behavior of light-cured packable composite resins. Dent Mater 2000;16(1):33-40.

7. Koplin C, Rodriguez G, Jaeger R. Multiaxial strength and stress forming behavior of four light-curable dental composites. J. Res. Pract. Dent. 2014;396766.

8. Takahashi H, Finger W, Endo T, Kanehira M, Koottathape N, Komatsu M, et al. Comparative evaluation of mechanical characteristics of nanofiller containing resin composites. American Journal of Dentistry. 2011;24(5):264-270.

9. Moraes RR, Goncalves LD, Lancellotti AC, Consani S, CorrerSobrinho L, Sinhoreti MA. Nanohybrid resin composites: nanofiller loaded materials or traditional microhybrid resins?. Operative dentistry. 2009;34(5):551-557.

10. The future of composite technology: Scientific Documentation by Ivoclar Vivadent AG Research \& Development Scientific Service Bendererstrasse 2 FL - 9494 Schaan Liechtenstein 2014:1-42.

11. Burtscher P, Rheinberger V. Germanium based photoinitiator as an alternative to camphorquinone/amine. IADR Abstract 2008; 1611.

12. Moszner N, Fischer U, Ganster B, Liska R, Rheinberger V. Benzoyl germanium derivatives as novel visible light photoinitiators for dental materials. Dent Mater. . 2008;24(7): 901-907.

13. Polydorou O, Manolakis A, Hellwig E, Hahn P. Evaluation of the curing depth of two translucent composite materials using a halogen and two LED curing units. Clin Oral Invest. 2008;12:45-51

14. Rueggeberg F A, Caughman W F, Curtis J W. Effect of light intensity and exposure duration on cure of resin composites. Oper Dent 1994;19:26-32.

15. Oberholzer T, Grobler S, Pameijer C, Hudson A. The effects of light intensity and method of exposure on the hardness of four light-cured dental restorative materials. International Dental Journal. 2003;53(4):211-215.

16. Dennison J, Yaman P, Seir R, Hamilton J. Effect of variable light intensity on composite shrinkage. J Prosthet Dent 2000; 84(5):499-505.

17. Asmussen E, Peutzfeldt A. Influence of UEDMA, BisGMA and TEGDMA on selected mechanical properties of experimental resin composites. Dent Mater. 1998;14(1):51-56.

18. Bona AD, Benetti P, Borba M, Cecchett D. Flexural and diametral tensile strength of composite resins. Braz Oral Res 2008;22(1):84-89.

19. Aguiar FH, Braceiro AT, Ambrosano GM, Lovadino JR. Hardness and diametral tensile strength of a hybrid composite resin polymerized with different modes and immersed in ethanol or distilled water media. Dent Mater. 2005; 21(12):1098-1103.

20. Geirsson J, Bayne SC, Swift EJ Jr, Thompson JY. Mechanical property characterization of a novel directly-placed ceramic restorative material. Am J Dent. 2004;17(6):417-421 